\title{
O PROCESSO DE PARCELAMENTO DO ESPAÇO RURAL NO MUNICÍPIO DE PONTA DE PEDRAS, PA, EM UMA PERSPECTIVA HISTÓRICA
}

\author{
Nilton Carlos Rosa ${ }^{1}$ \\ Sandra Maria Fonseca da Costa ${ }^{2}$
}

Resumo: O objetivo do presente artigo é apresentar uma avaliação do processo de parcelamento da terra no município de Ponta de Pedras, PA, a partir de uma análise dos registros do Cartório de Registro Civil Antônio Malato, com o intuito de levantar as informações referentes às famílias tradicionais, o número de propriedades de cada família e as propriedades desmembradas de antigas Sesmarias e Sorte de Terras. Este município tem sua origem ligada ao surgimento de Sesmarias, introduzidas no Brasil Colônia, no século XVI/XVII. Neste sentido, uma discussão sobre o período colonial brasileiro será realizada para a compreensão deste estudo.

Palavras-chave: Sesmarias; Terra; Famílias.

\footnotetext{
1 Universidade do Vale do Paraíba, Brasil. E-mail: niltoncarlos.rosa4@gmail.com.

2 Universidade do Vale do Paraíba, Brasil. E-mail: sandra@univap.br.
} 